\title{
Observation and publication of infrequently observed behavior
}

\author{
Naofumi Nakagawa ${ }^{1}$
}

Received: 31 May 2021 / Accepted: 2 June 2021 / Published online: 12 June 2021

(c) Japan Monkey Centre 2021

I am writing this editorial as the President of the Primate Society of Japan (PSJ) at the request of new Editor-in-Chief, Masayuki Nakamichi. The journal Primates has been a semiofficial journal of PSJ since 2003, when Springer became the publisher of the journal (Sugiyama 2003). The memorandum exchanged between the Japan Monkey Center (JMC) and PSJ states that the Editor-in-Chief is selected and commissioned by the Director-General of JMC in consultation with the President of PSJ. With the resignation of Tetsuro Matsuzawa as Editor-in-Chief, I recommended Prof. Masayuki Nakamichi of Osaka University to Gen'ichi Idani, Director-General, as a candidate for the post of new Editor-in-Chief.

During my research career on Japanese macaques (Macaca fuscata), patas monkeys (Erythrocebus patas, Fig. 1) and tantalus monkeys (Chlorocebus tantalus), Prof. Nakamichi and I have collaborated on several study projects on Japanese macaques, and we co-edited the first English book featuring a broad range of field research on Japanese
Fig. 1 Diurnal birth as a species-typical pattern of patas monkeys in Kala Maloue National Park, Cameroon (Nakagawa 1992, see also Chism et al. 1983) (photo taken by Naofumi Nakagawa)

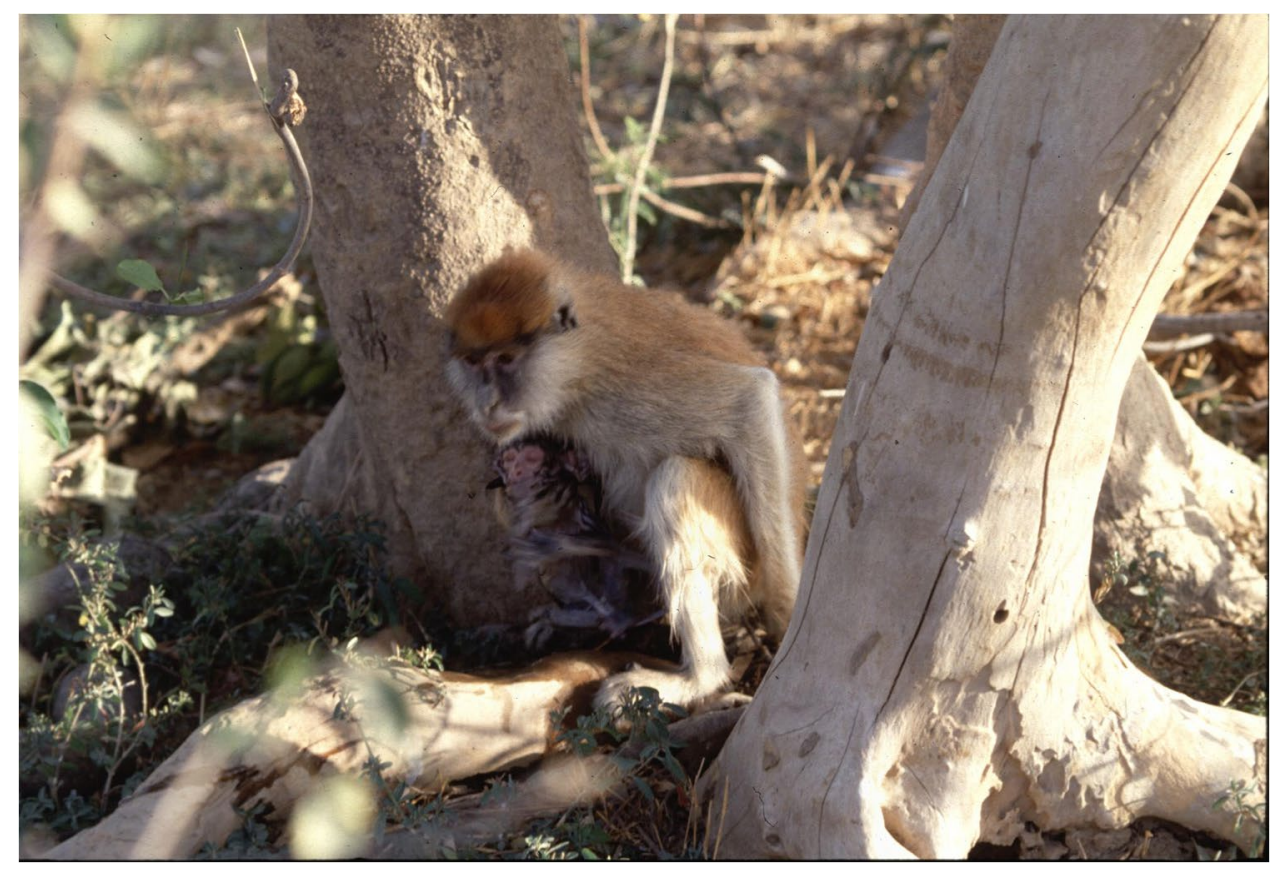

N. Nakagawa: the president of the Primate Society of Japan, Associate Editor, PRIMATES.

Naofumi Nakagawa

nakagawa@jinrui.zool.kyoto-u.ac.jp

1 Graduate School of Science, Kyoto University,

Kitashirakawa-Oiwake-cho, Sakyo-ku, Kyoto 606-8502,

Japan 
macaques, entitled "The Japanese Macaques" (Nakagawa et al. 2010). Some anecdotal records were cited in some chapters in this book, and Nakamichi and his students have frequently published case reports of infrequently observed behaviors of Japanese macaques. In Primates these include Nakamichi et al. (1992) for birth, Yamada and Nakamichi (2006) for infanticide, and Nakamichi et al. (2010) for grandmaternal care of grandchildren. In Primate Research, the official journal of PSJ, these include Nakamichi et al. (2004) for birth and maternal behavior, Onishi et al. (2010) for aggression against a flying squirrel, Ueno et al. (2014) for maternal behavior, and Katsu et al. (2014) for stillbirths.

Ramsay and Teichroeb (2019) examined the rate and content of anecdotal publications from 2000 to 2016 in the four major international journals specific to primatology [Primates, International Journal of Primatology (IJP), Folia Primatologica (FP), and American Journal of Primatology $(A J P)]$. Their review found that Primates and $F P$ published significantly more anecdotal accounts than $I J P$ and $A J P$ (Fig. 2). There was no significant change over time in Primates or $I J P$, while the publication of anecdotes significantly decreased from 2000 to 2016 in AJP and FP. Infanticide, predation, and births were the top three subjects in these publications. The authors discussed the different trends among the journals as follows: "Primates continued acceptance of anecdotes can be seen as tied to the Japanese tradition of narrative primatology," while "in 2011, AJP removed its Brief Reports" publication option, which is where most anecdotes would be sent," partly "because brief reports were rarely cited" and consequently lowered the journal's impact factor. Moreover, to the best of my knowledge, many "Brief Reports" used to appear in $F P$, but disappeared in 2005. On the other hand, Primates created a new forum-"News and Perspectives"-instead of "Short Communications" in 2009 , so as to accept only case studies with high news value (Nishida 2009). Although Primates maintained the option to publish anecdotes, the overall rate of anecdotal publications in international primatological journals decreased from 2000 to 2016 (Ramsay and Teichroeb 2019). As a measure against a drought of anecdotal studies in international primatological journals, PSJ decided to accept English-language "Short Reports" (Furuichi 2010), which have been published periodically in Japanese (1-2 articles per year) since the first issue of Primate Research in 1985 (Nakagawa 2017), and really supported this feature [e.g. Hayakawa et al. (2011) Kuze et al. (2011), Ogawa et al. (2019)]. As Japanese-language "Short Reports" and other categories of articles, such as original articles and review articles, provide English summaries, these can be freely accessed through the Primate Research website on J-Stage, the online journal platform operated by the Japanese Science and Technology Agency (https://www.jstage.jst.go.jp/browse/psj/list/-char/en).

I do not know the reason, but the drought of "Brief Reports" appears to be over. FP revived "Brief Reports" as "Short Communications" in 2016 and in the same year IJP created "News \& Views," which are short communications briefly reporting new observations or results (Setchell et al. 2016). More surprisingly, the journal Behaviour invited
Fig. 2 Yearly rates of anecdote publications in the four international journals specific to primatology from 2000 to 2016 (reprinted with permission from Ramsay and Teichroeb 2019, published by John Wiley and Sons)

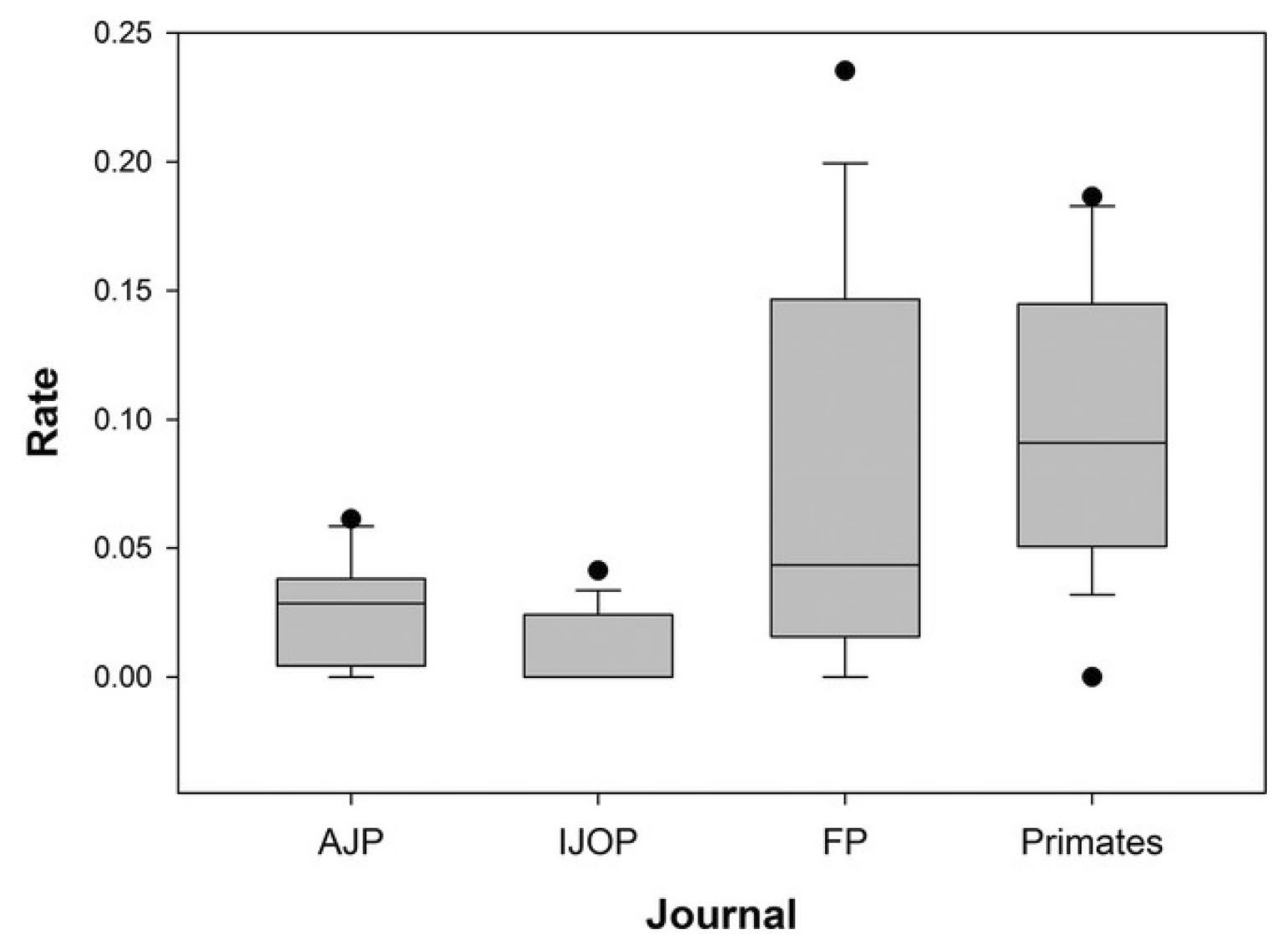


scholars who have anecdotal evidence of unique behavior in any species to submit a report as a "Commentary" (Kret and Roth 2020).

In 2008 Prof. Nakamichi, his colleague Dr. Kazunori Yamada, and I initiated a new project entitled "Exchange and Integration of Information on Infrequently Observed Behaviors in Japanese Macaques" (Nakamichi et al. 2009). At the kick-off symposium for this project, a paper-based questionnaire on infrequently observed behaviors (IOBs) in Japanese macaques was given to primatologists. This survey aimed to provide basic information on the rarity of various behaviors. The questionnaire asked about direct observation of 36 types of IOBs, requiring the answers "yes," "no," or "impossible to answer because of ambiguous memory or lack of awareness of this behavior." In total, 39 answer sheets were obtained from 32 respondents. The top $10 \mathrm{IOBs}$, with the number of respondents answering "yes" in parentheses, are as follows: mating interruption by juveniles (1); simultaneously nursing different-aged offspring (1); use of tools (1); single-mount ejaculation (2); transporting older offspring (2); nursing older offspring (2); simultaneously transporting different-aged offspring (3); pulling the hair of a female's chin as a courtship behavior by a male (4); twin birth (4); and (diurnal) birth (6). Some IOBs, such as mating interruption by juveniles, pulling the hair of a female's chin as a courtship behavior, and simultaneously transporting different-aged offspring, seem to be partly due to ambiguous memory or lack of awareness of this behavior (Nakagawa et al. 2011).

I conducted a web-based questionnaire of IOBs in Japanese macaques using video footage as a reference for the IOBs, to improve on this gap in the previous method. This questionnaire was conducted in March 2020, when the first wave of the COVID-19 pandemic hit Japan. Since the results have just been published in the most recent issue 37(1) of Primate Research (Nakagawa 2021), I provide a summary as follows: In total, 62 answer sheets were returned. As expected, the incidence of "impossible to answer because of lack of awareness" by respondents decreased, due to the use of video footage. My primary objective is to extract interpopulation differences that could be considered cultural by focusing on IOBs that can be seen in one population but not in another, in accordance with the "method of exclusion" (Kruetzen et al. 2007) employed in a landmark paper on chimpanzee culture (Whiten et al. 1999).

Following the percentage ( $p$ ) of respondents answering "yes" to all giving definite answers ("yes" or "no"), each population was classified as "frequently seen" $(100 \% \geq p>75 \%)$, "seen" $(75 \% \geq p>0 \%)$, or "never seen" $(0 \%)$. To enhance the reliability of the data, respondents were limited to those whose research period was 1 year or longer, direct observation time was $2 \mathrm{~h}$ or longer per day, and the closest distance to the macaque was less than $5 \mathrm{~m}$ during observation (hereafter defined as a "long-term intensive observer"). Behaviors that were "never seen" in at least one population, but were "frequently seen" in at least one population, "seen" in others, and that cannot be explained by environmental differences, can be considered cultural. The following behaviors were extracted: stone-handling and embracing behaviors, both of which have known cultural variations [Huffman et al. (2010) and Nakagawa et al. (2015), respectively], along with selfwrist biting and breaking-bubbles solo play. Nakagawa et al. (2015) showed that despite functional similarity (tension reduction), the forms of embracing in Yakushima macaques were slightly different from those previously reported in Kinkazan [Shimooka and Nakagawa (2014)]. Ventro-ventral embraces as well as ventro-lateral (Fig. 3a) and ventro-dorsal embraces were observed in Yakushima, while only the ventro-ventral embrace was observed in Kinkazan (Fig. 3b). Such a difference was confirmed by questionnaire data from at least two long-term intensive observers per population; all three forms were "frequently seen" in Yakushima, while in Kinkazan only the ventroventral embrace was "frequently seen," whereas the remaining two were "never seen." Moreover, none of the forms of embrace were seen in Arashiyama or Koshima (Nakagawa 2021).

The behaviors that were "seen" in only one population but "never seen" in others cannot be called cultural at this point, as they are not likely to have spread to an extent that could be considered habitual; instead, they should be regarded as behavioral innovations for Japanese macaques. The following behaviors were extracted: rump-rump contact between males; detachment of branches for branch-dragging social play; and pulling the hair of a female's chin as courtship by a male. Ms. Maho Hanzawa, my student, published a "Short Report" on the first record of rump-rump contact behaviors between males in Yakushima (Hanzawa 2020). Two video-recorded cases out of eight cases observed in $477.8 \mathrm{~h}$ showed that one is an "RR" type in which two males touch their rumps with each other (Fig. 4a), while the other is an "RT" type in which one male touches its rump to the lateral torso of the other (Fig. 4b) (see also video footage provided as supplemental material on the website of Primate Research, https://www.jstage.jst.go.jp/article/psj/36/2/36_36.015/_ article/-char/en\#supplimentary-materials-wrap). Both of these cases concern interactions between the alpha-male and a beta-male of a group just after an intergroup encounter. Her tentative interpretation is that this behavior might function as tension reduction, with similarities to bonobos (Pan paniscus) in which the RR type of contact is well documented (Hanzawa 2020). 
Fig. 3 a Ventro-lateral embrace between adult female Japanese macaques in Yakushima (photo taken by Naofumi Nakagawa). b Ventro-ventral embrace between adult female Japanese macaques in Kinkazan (photo taken by Naofumi Nakagawa)
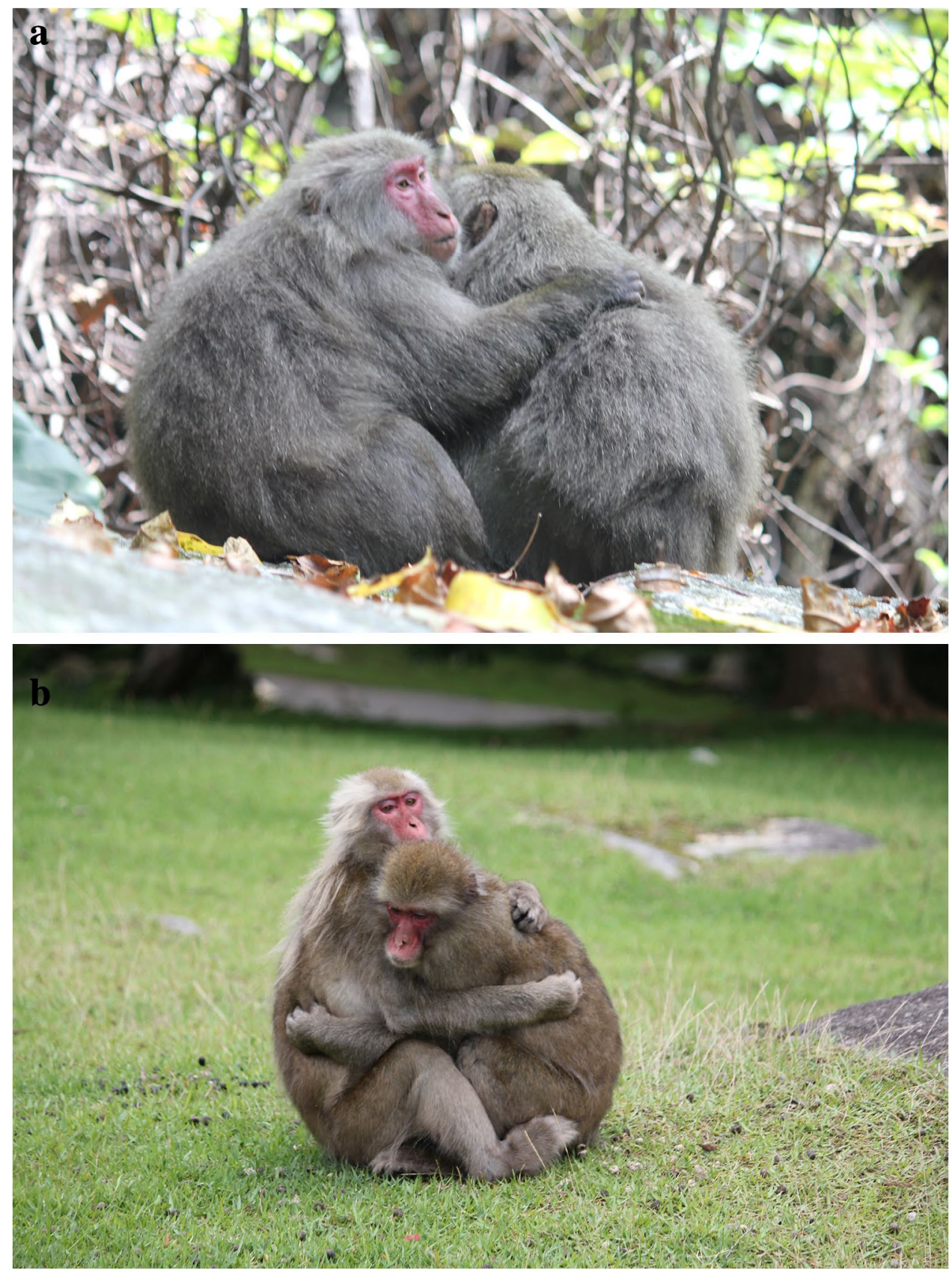

While rump-rump contact behavior was "seen" only in Yakushima, it was "never seen" in any other population, including Shimokita, Kinkazan, Arashiyama, Awajishima, Kanba-no-taki (previously called Katsuyama), and Koshima, where questionnaire data were obtained from at least two long-term intensive observers. When excluding the condition "at least two long-term intensive observers," Takasakiyama, Funakoshiyama, and nine crop-raiding populations also provided evidence for "never seen."

As the saying "absence of evidence is not evidence of absence" makes clear, it is difficult to prove absence. I believe that the "never seen" answer from multiple longterm intensive observers could be supporting evidence for absence. However, it is also true and important that novel behaviors, such as embracing and rump-rump contact behavior, were discovered so long after the start of long-term intensive observations of Japanese macaques on December 3, 1948, which Prof. Jun'ichiro Itani described as the beginning of Japanese primatology (Itani 1991). Primate Research and Primates will continue to provide a platform for accounts of infrequently observed behaviors in primate species. 
Fig. 4 a RR type of rump-rump contact between adult male Japanese macaques in Yakushima (snapshot of a video taken by Maho Hanzawa). b RT type of rump-rump contact between adult male Japanese macaques in Yakushima (snapshot of a video taken by Maho Hanzawa)
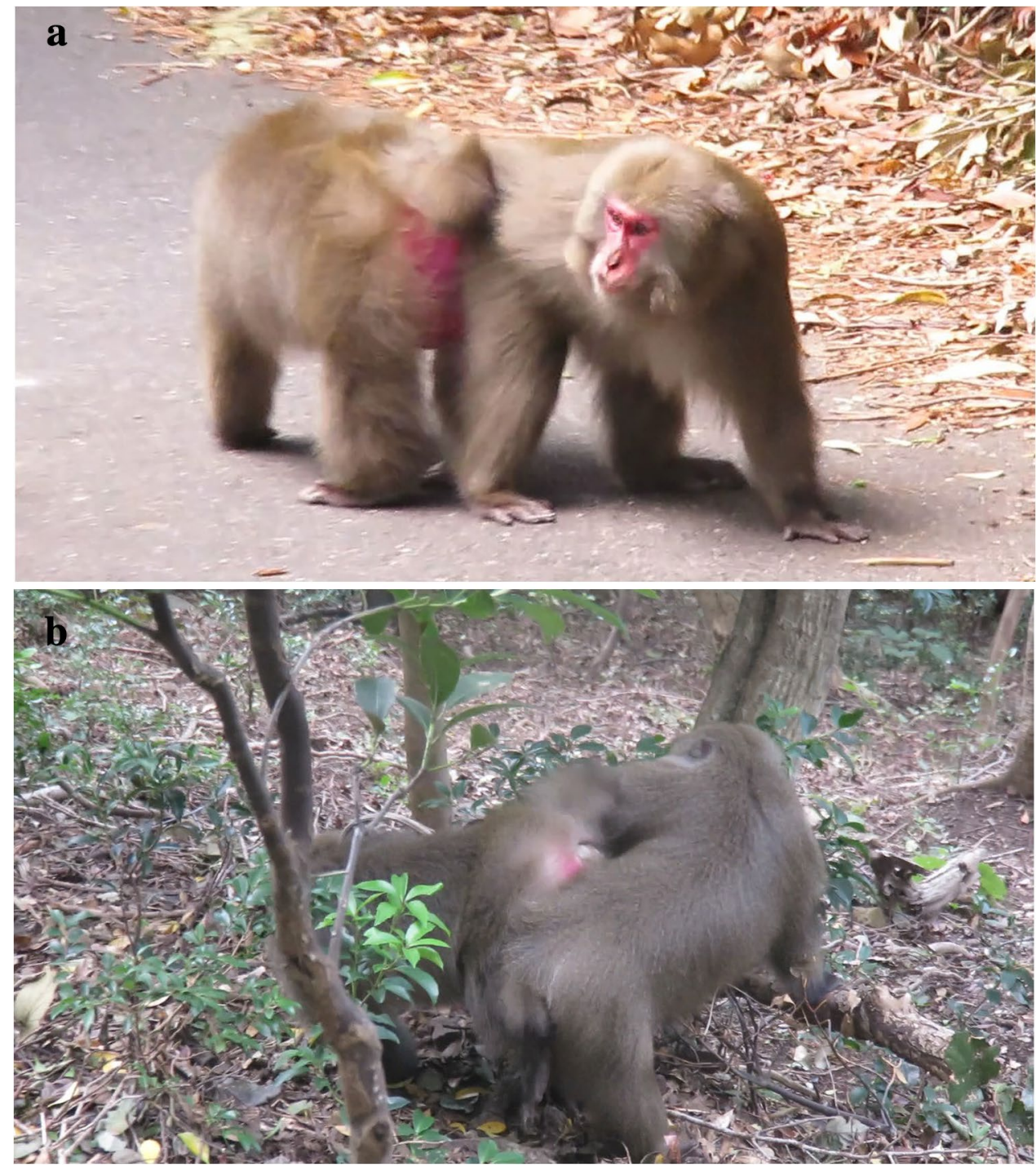

\section{References}

Chism J, Olson DK, Rowell TE (1983) Diurnal births and perinatal behavior among wild patas monkeys: evidence of an adaptive pattern. Int J Primatol 4:167-184

Furuichi T (2010) Editor's note. Primate Res 26:280 ((in Japanese))

Hanzawa M (2020) First record on "rump-rump contact" behavior between males in wild Japanese macaques (Macaca fuscata) on Yakushima Island. Primate Res 36:33-39 (in Japanese with English summary)

Hayakawa S, Hernandez AD, Suzuki M, Sugaya K, Koda H, Hasegawa H, Endo H (2011) Necropsy case report for an old wild Japanese macaque (Macaca fusucata yakui) from Yakushima Island. Primate Res 27:3-10

Huffman MA, Leca JB, Nahallage CAD (2010) Cultured Japanese macaques: a multidisciplinary approach to stone handling behavior and its implications for the evolution of behavioral tradition in nonhuman Primates. In: Nakagawa N, Nakamichi M, Sugiura H (eds) The Japanese macaques. Springer, Tokyo, pp 191-219

Itani J (1991) Saru, Hito, Africa: Watashi no Rirekisho (Monkeys, humans, and Africa: my curriculum vitae). Nihon-Keizai-shinbunsha, Tokyo (in Japanese)
Katsu N, Suzumura T, Yamada K, Nakamichi M (2014) Parturition and perinatal behavior in Japanese macaques for stillbirths in Arashiyama and Koshima. Primate Res 30:163-172

Kret ME, Roth TS (2020) Anecdotes in animal behaviour. Behaviour 157:385-386

Kruetzen M, van Schaik C, Whiten A (2007) The animal cultures debate: response to Laland and Janik. Trends Ecol Evol 22:6

Kuze N, Kawabata H, Yamazaki S, Kanamori T, Malim TP, Bernard $\mathrm{H}$ (2011) A wild Borneo orangutan carries large numbers of branches on the neck for feeding and nest building in the Danum Valley Conservation Area. Primate Res 27:21-26

Nakagawa N (1992) Diurnal birth of patas monkeys for surviving in savannah. Anima 243:80-85 (in Japanese)

Nakagawa N (2017) Studies on "PRIMATE RESEARCH" (new version). Primate Res 33:59-68 (in Japanese with English summary)

Nakagawa N (2021) Report on a web-based questionnaire on infrequently observed behaviors in Japanese macaques, referring to their video footage, with special reference to cultural differences among populations. Primate Res 37:17-34 (in Japanese with English summary) 
Nakagawa N, Nakamichi M, Sugiura H (eds) (2010) The Japanese macaques. Spriger, Tokyo

Nakagawa N, Nakamichi M, Yamada K (2011) Report on the questionnaire for infrequently-observed behaviors in Japanese macaques. Primate Res 27:111-125 (in Japanese with English summary)

Nakagawa N, Matsubara M, Shimooka Y, Nishikawa M (2015) Embracing in a wild group of Yakushima macaques (Macaca fuscata yakui) as an example of social customs. Curr Anthropol 56:104-120

Nakamichi M, Imakawa S, Kojima Y, Natsume A (1992) Paturition in a free-ranging Japanese monkey (Macaca fuscata). Primates 33:413-418

Nakamichi M, Yamada K, Ohtsuka N, Imakawa S, Yasuda J, Shizawa Y (2004) Case reports on parturition and maternal behavior in a free-ranging group of Japanese monkeys at Katsuyama. Primate Res 20:31-43 (in Japanese with English summary)

Nakamichi N, Yamada K, Nakagawa N (2009) Exchange and integration of information on rarely- or infrequently-observed behaviors in Japanese macaques. Primate Res 25:15-20 (in Japanese)

Nakamichi M, Onishi K, Yamada K (2010) Old grandmothers provide essential care to their young granddaughters in a freeranging group of Japanese monkeys (Macaca fuscata). Primates $51: 171-174$

Nishida T (2009) News and Perspectives. Primates 50(3):195-195. https://doi.org/10.1007/s10329-009-0155-0

Ogawa H, Paudel PK, Koirala S, Khatiwada S, Chalise MK (2019) Social interactions between rhesus macaques (Macaca mulatta) and Assamese macaques (M. assamensis) in Nepal: why do male Rhesus macaques follow social groups of Assamese macaques? Primate Res 35:45-51
Onishi K, Yamada K, Nakamichi M (2010) Aggressive response of Japanese macaques toward a Japanese giant flying squirrel. Primate Res 26:35-49 (in Japanese with English summary)

Ramsay MS, Teichroeb JA (2019) Anecdotes in primatology: temporal trends, anthropocentrism, and hierarchies of knowledge. Am Anthropol 121:680-693

Setchell JM, Fernandez-Duque E, Higham JP, Rothman JM, Shülke O (2016) Editorial: changes and clarifications to the policies of the International Journal of Primatology to promote transparency and open communication. Int J Primatol 37:617-627

Shimooka Y, Nakagawa N (2014) Functions of an unreported "rockingembrace" gesture between female Japanese Macaques (Macaca fuscata) in Kinkazan Island, Japan. Primates 55:327-335

Sugiyama Y (2003) Message from the editor-in-chief. Primates 44:1

Ueno M, Yamada K, Nakamichi M (2014) Maternal responses to a 1 -year-old male offspring with severe injury in a free-ranging group of Japanese macaques. Primate Res 30:157-162

Whiten A, Goodall J, McGrew WC, Nishida T, Reynolds V, Sugiyama Y, Tutin CEG, Wrangham RW, Boesch C (1999) Cultures in chimpanzees. Nature 399:682-685

Yamada K, Nakamichi M (2006) A fatal attack on an unweaned infant by a non-resident male in a free-ranging group of Japanese macaques (Macaca fuscata) at Katsuyama. Primates 47:165-169

Publisher's Note Springer Nature remains neutral with regard to jurisdictional claims in published maps and institutional affiliations. 